\title{
THE EVOLVING ROLE OF PUBLIC HEALTH IN THE DELIVERY OF HEALTH CARE
}

\author{
Hani K. Atrash ${ }^{1}$, Richard Carpentier ${ }^{2}$
}

\begin{abstract}
:
Health care is conventionally regarded as the diagnosis, treatment, and prevention of disease, illness, injury, and other physical and mental impairments in humans. Some examples of public health measures include ensuring a safe and healthy environment, clean water, safe workplaces; promotion of healthy behaviors such as hand washing and breast feeding; and, preventing infectious diseases such as delivery of vaccinations and distribution of condoms to control the spread of sexually transmitted diseases. How we define the quality of public health at any given time must be compatible with future generations enjoying health in an equivalent way. Public health practitioners must also integrate sustain ability in the definition of public health.
\end{abstract}

Key words: public health; medicine; medical specialities; impairments

\section{Health Care:}

Health care is conventionally regarded as the diagnosis, treatment, and prevention of disease, illness, injury, and other physical and mental impairments in humans. These services are delivered by the health care system at the local, state, and national levels by practitioners in medicine, chiropractic, dentistry, nursing, pharmacy, allied health, and other care providers. However, the term health care provider extends far beyond practitioners trained in caring for individuals to those involved in setting policies, ensuring financing, managing programs and those providing administrative support to clinical health care providers. The World Health Organization proposes that "a health system consists of all organizations, people and actions whose primary intent is to promote, restore or maintain health. This includes efforts to influence determinants of health as well as more direct health-improving activities. A health system is therefore more than the pyramid of publicly owned facilities that deliver personal health services. It includes, for example, a mother caring for a sick child at home; private providers; behavior change programs; vector-control campaigns; health insurance organizations; occupational health and safety legislation. It includes inter-sector al action by health staff, for example, encouraging the ministry of education to promote female education, a well-known determinant of better health."1

According to the World Health Organization, "a well-functioning health system responds in a balanced way to a population's needs and expectations by:

- Improving the health status of individuals, families and communities

- Defending the population against what threatens its health

- Protecting people against the financial consequences of ill-health

- Providing equitable access to peoplecentered care, and

- Making it possible for people to participate in decisions affecting their health and health system".2

\section{"Public Health" as a Component of Health Care}

While some of the above needs and expectations can be met through high quality, accessible direct clinical services, most can only be accomplished through a strong "public health" system. And while clinical services focus on the health of one individual at a time, public health has

1 MD, MPH Director, Division of Blood Disorders Centers for Disease Control and Prevention.

2 PhD Manager, Research Ethics Board Secretariat Science Policy Directorate Strategic Policy Branch Health Canada. Corresponding author: hatrash@hrsa.gov

Suggested citation: Atrash HK, Carpentier R. The evolving role of public health in the delivery of health care. J. Hum. Growth Dev. 2012; 22(3): 396-399

Manuscript submitted Oct 20 2012, accepted for publication Oct 232012. 
a much broader focus and works to ensure the health and wellbeing of groups of people in a neighborhood, city, region, country or many countries, and its role and functions go far beyond providing direct services to individuals or to communities. Public health works to improve health and quality of life through prevention and treatment of disease and through promotion of healthy behaviors. Some examples of public health measures include ensuring a safe and healthy environment, clean water, safe workplaces; promotion of healthy behaviors such as hand washing and breast feeding; and, preventing infectious diseases such as delivery of vaccinations and distribution of condoms to control the spread of sexually transmitted diseases. Despite these differences, the approaches used for providing public health services are similar to those used for providing clinical care services. For a clinical care provider, an individual presents with a problem or a complaint; the first step in providing care is to ask the question, what is the problem and to define the problem and make a diagnosis; the next step is to identify a cause of the problem; then to decide what is the best way to solve the problem and decide on treatment; offer treatment, evaluate the effect of treatment and follow up by continuing or modifying treatment. In public health, we follow the same procedure. A community or population has a problem. The first step is to ask the question, what is the problem, and to make a diagnosis; the next step is to identify a cause; then to decide what works and decide on an intervention or a program; implement the program, evaluate its effect and follow up by continuing or modifying the intervention.

Public health is a basic component of health care systems. However, to many people the definition and role of public health are not clear. The definition and understanding of public health and its role has changed continuously over time, often affected by current events and the perceived needs for health protection and disease prevention. Starting with early civilization, communities recognized that polluted water and lack of proper waste disposal spread communicable diseases and religions attempted to regulate behavior that specifically related to health, from types of food eaten, to regulating certain indulgent behaviors, such as drinking alcohol or sexual relations. The role of public health evolved with advanced civilization and the reduced threats of common infectious diseases to address problems associated with risky behaviors and new technology and their accompanying challenges; examples include: smoking, injury related to motor vehicle accidents and firearms, wars and civil conflicts, famine and malnutrition, migration and displaced populations, obesity, unplanned pregnancies and induced abortions, new infectious diseases not encountered earlier (HIV/SARS, West Nile Virus/
Hunta Virus), and emergency preparedness to deal with natural and man-made threats and hazards. Over the past few decades, we witnessed an evolution of public health to respond to these emerging challenges accompanied with an increased interest in the development of a better definition of public health and its functions, roles and responsibilities.

\section{Public Health: Definition, Functions, Services}

The classic definition of "public health" by Winslow (1920) describes it as "the science and art of preventing disease, prolonging life, and promoting physical health and efficiency through organized community efforts for the sanitation of the environment, the control of community infections, the education of the individual in principles of personal hygiene, the organization of medical and nursing services for the early diagnosis and preventive treatment of disease, and the development of the social machinery which will ensure to every individual in the community a standard of living adequate for the maintenance of health."33 More recently, the American Public Health Association defined public health as "the practice of preventing disease and promoting good health within groups of people, from small communities to entire countries." ${ }^{4}$ In 1988, the Institute of Medicine defined public health as "what we, as a society, do collectively to assure the conditions in which people can be healthy".5 Finally, in 2003, the Canadian Standing Senate Committee on Social Affairs, Science and Technology issued a report titled "Reforming Health Protection and Promotion in Canada: Time to Act". In this report, the Committee stated that they find the term "public health" often confused with "publicly funded health care", and therefore they deliberately avoided the use of the term "public health"; instead, they adopted the terminology "health protection and promotion". The Committee considered" health protection and promotion" to encompass "disease surveillance, disease and injury prevention, health protection, health emergency preparedness and response, health promotion, and relevant research undertakings". ${ }^{6}$

The Institute of Medicine (IOM) further identified three core functions to be provided by all public health agencies. These functions include: 1. Assessment, defined as assessment and monitoring of the health of communities and populations at risk, to identify health problems and priorities 2. Policy development, defined as formulating public policies, in collaboration with community and government leaders, to solve identified local and national health problems and priorities, and 3. Assurance, defined as assuring that all populations have access to appropriate and cost effective care, including health promotion and disease prevention services, and evaluation of the effectiveness of that care. ${ }^{5}$ 
In 1994, the Core Public Health Functions Steering Committee, led by the Centers for Disease Control and Prevention, defined 10 essential services of public health, and developed the framework to provide a working definition of public health and a guiding framework for the responsibilities of local public health systems. This steering committee included representatives from United States Public Health Service agencies and other major public health organizations. The 10 essential services were aligned to support the previously defined core functions. ${ }^{7}$ Two essential services support the core function of Assessment: monitoring health status to identify community health problems; and, diagnosing and investigating health problems and health hazards in the community. Three services support the core function of Policy development: informing, educating and empowering people about health issues; mobilizing community partnerships to identify and solve health problems; and, developing policies and plans that support individual and community health efforts. And, four services support the core function of Assurance: enforcing laws and regulations that protect health and ensure safety; linking people to needed personal health services and assuring the provision of health care when otherwise unavailable; assuring a competent public health and personal health workforce; and, evaluating effectiveness, accessibility, and quality of personal and population-based health services. Finally, the committee added a tenth essential public health service and recommended that public health should promote research to provide insights and innovative solutions to health problems.

\section{The Evolving Role of Public Health}

Throughout history, approaches to health have reflected changes in the population needs and a shift in our thinking about how health is defined. Attention to public health and its relationship to the health of populations increased and disappeared based on current events. The definition of health has changed to align with our changing understanding, expectations and priorities. For example, the original definition of health was simply the absence of disease. In 1946, the World health Organization adopted a new definition still being used of "health is a state of complete physical, mental and social well-being and not merely the absence of disease." 8 More recently, The Public Health Agency of Canada took the concept of public health one step further and re-defined it as population health. The population health approach "recognizes that health is a capacity or resource rather than a state, a definition which corresponds more to the notion of being able to pursue one's goals, to acquire skills and education, and to grow. This broader notion of health recognizes the range of social, economic and physical environmental factors that contribute to health. The best articulation of this concept of health is "the capacity of people to adapt to, respond to, or control life's challenges and changes"." The population health approach is based on an assumption that at every stage of life, health is determined by complex interactions between social and economic factors, the physical environment and individual behavior. It is the combined influence of the determinants of health that determines health status". Determinants of health are factors, behaviors and conditions that interrelate to influence health. As part of its population health approach, the Public Health Agency of Canada recognized 12 determinants of health: income and social status; social support networks; education and literacy; employment/ working conditions; social environments; physical environments; personal health practices and coping skills; healthy child development; biology and genetic endowment; health services; gender; and, culture. ${ }^{9}$ It is clear from the above definitions of "public health" and "population health" that, first, public health plays a significant role in the delivery of health care, and second, that this role has expanded over the years with the expansion of the needs and expectations of communities.

Although the main responsibility for public health resides with the departments of health at the local, state or national levels, the success of public health depends on the coordination of efforts and collaboration between these departments and workers in other components of the health care system, other government agencies, communitybased organizations, as well as private organizations. The success of the health care systems is the shared responsibility of many sectors of the private and public sectors.

Finally, as we have seen, health is often defined as a result of complex interactions. More than two decades ago, Maurice King reminded us that 'Health is a Sustainable State'10, that is something constantly on the move and depending on constant attention, active maintenance and care. In particular, that the achievement of a good quality of public health depends on our ability to make the right choices regarding the environment that determines the current health status of a population, but also to make the right choices and take the appropriate actions to prevent foreseeable threats. How we define the quality of public health at any given time must be compatible with future generations enjoying health in an equivalent way. Public health practitioners must also integrate sustain ability in the definition of public health. ${ }^{11}$ 


\section{REFERENCES}

1. Everybody's business. Strengthening health systems to improve health outcomes: WHO's framework for action. World Health Organization, 2007. Accessed October 15, 2012. http://www.who.int/healthsystems/ strategy/everybodys_business.pdf

2. Key components of a well functioning health system. World Health Organization, 2010. Accessed October 15, 2012. http:// w w w. who.int/health system s/ EN_HSSkeycomponents.pdf

3. Winslow CEA. The untilled fields of public health. New York, NY: Health Service, New York County Chapter of the American Red Cross; 1920.

4. American Public Health Association. Accessed October 15, 2012. http://www.apha.org/NR/ rdonlyres/C57478B8-8682-4347-8DDFA1E24E82B919/0/what_is_PH_May1_Final.pdf

5. The future of the public's health in the $21^{\text {st }}$ century.Institute of Medicine. The National Academies Press, Washington, DC, 2003.

6. Standing Senate Committee on Social Affairs, Science and Technology,Reforming Health
Protection and Promotion in Canada: Time to Act, Fourteenth Report, 37th Parliament, 2nd Session, November 2003. Accessed October 15, 2012.http://www.parl.gc.ca/Content/SEN/ Committee/372/soci/rep/repfinnov03-e.pdf

7. Ten Essential Public Health services. Centers for Disease Control and Prevention. Accessed October 15, 2012. http://www.cdc.gov/ nphpsp/essentialservices.html

8. Preamble to the Constitution of the World Health Organization as adopted by the International Health Conference, New York, 1922 June, 1946; accessed October 15, 2012. http://www.who.int/about/definition/en/ print.html

9. What is population health? Public Health Agency of Canada. Accessed October 15, 2012. http:/ /www.phac-aspc.gc.ca/ph-sp/approachapproche/index-eng.php

10. King, M. Health is a sustainable state. Lancet, 1990, 336: 664-667.

11. McMichael, AJ. Population health as the 'bottom line' of sustainability: a contemporary challenge for public health researchers. European Journal of Public Health, 2006, 16: 579-582. 